\title{
Autonomic dysfunction following traumatic brain injury: translational insights
}

\author{
Fatima Khalid, MS, ${ }^{1}$ George L. Yang, MD, ${ }^{2}$ Jennifer L. McGuire, PhD, ${ }^{2,3}$ Matthew J. Robson, PhD,, 34 \\ Brandon Foreman, MD, ${ }^{2,3,5}$ Laura B. Ngwenya, MD, PhD, ${ }^{2,3,5}$ and John N. Lorenz, PhD'
}

\begin{abstract}
Departments of ${ }^{1}$ Pharmacology and Systems Physiology and ${ }^{2}$ Neurosurgery, College of Medicine; ${ }^{3}$ Collaborative for Research on Acute Neurological Injuries; ' Division of Pharmaceutical Sciences, James L. Winkle College of Pharmacy; and ${ }^{5}$ Department of Neurology and Rehabilitation Medicine, College of Medicine, University of Cincinnati, Ohio
\end{abstract}

\begin{abstract}
Although there is a substantial amount of research on the neurological consequences of traumatic brain injury (TBI), there is a knowledge gap regarding the relationship between TBI and the pathophysiology of organ system dysfunction and autonomic dysregulation. In particular, the mechanisms or incidences of renal or cardiac complications after TBI are mostly unknown. Autonomic dysfunction following TBI exacerbates secondary injury and may contribute to nonneurologial complications that prolong hospital length of stay. Gaining insights into the mechanisms of autonomic dysfunction can guide advancements in monitoring and treatment paradigms to improve acute survival and long-term prognosis of TBI patients. In this paper, the authors will review the literature on autonomic dysfunction after TBI and possible mechanisms of paroxysmal sympathetic hyperactivity. Specifically, they will discuss the link among the brain, heart, and kidneys and review data to direct future research on and interventions for TBI-induced autonomic dysfunction.
\end{abstract}

https://thejns.org/doi/abs/10.3171/2019.8.FOCUS19517

KEYWORDS traumatic brain injury; autonomic dysfunction; autoregulation; kidney; cardiovascular

$\mathrm{T}$ RAUMATIC brain injury (TBI) affects over 2.9 million people in the US and over 68 million worldwide annually. In 2010, the estimated economic cost of TBI-related emergencies was $\$ 76.5$ billion. ${ }^{56}$ Despite efforts to expand our knowledge and advance treatment for patients with TBI, the systemic effects of brain injury, as well as its relevance to patient prognosis, is largely unknown. Autonomic nervous system (ANS) dysregulation after TBI is grossly understudied, yet preventing or treating dysautonomia has the potential to dramatically improve both initial patient survival and long-term outcomes, ultimately reducing the economic burden of TBI.

The ANS governs homeostatic control over different organs in the body. It is composed of the sympathetic and parasympathetic pathways working in concert with the endocrine system to regulate cardiac, renal, adrenal, homeothermic, and enteric function. Autonomic dysfunction can occur when there is an imbalance in the regulation or function of the parasympathetic and sympathetic pathways, resulting in organ system dysfunction.

In injuries such as burns, hyperactivity of the sym- pathetic nervous system may be an adaptive response to ensure that damaged tissues receive adequate oxygen. However, in severe TBI this hyperadrenergic state can be maladaptive, resulting in damage to the myocardium and other critical organs..$^{11,12}$ Despite the frequency of ANS dysregulation after TBI, it is usually undiagnosed and undertreated. It was only in 2010 that the term paroxysmal sympathetic hyperactivity (PSH) was suggested as the unifying term for the clinical condition ${ }^{49}$ and not until 2014 that a conceptual definition and diagnostic criteria were established. ${ }^{2}$

Neurocritical care focuses on maintaining stable cardiovascular and respiratory function after TBI, with an emphasis on managing symptomology and minimizing inflammation and secondary brain injury. As stated in the 2017 guidelines for management of severe TBI, the goal is to maintain adequate cerebral perfusion. ${ }^{7}$ However, the syndrome of PSH, commonly referred to as "storming," frequently complicates the clinical picture and is likely heterogeneous in nature. At this time, a treatment model for PSH is incomplete, and the level of evidence support-

ABBREVIATIONS AKI = acute kidney injury; $A N P=$ atrial natriuretic peptide; $A N S=$ autonomic nervous system; $A R C=$ augmented renal clearance; $C K D=$ chronic kidney damage; ICP = intracranial pressure; NTS = nucleus tractus solitarius; PSH = paroxysmal sympathetic hyperactivity; RVLM = rostral ventrolateral medulla; $S A H=$ subarachnoid hemorrhage; SFO = subfornical organ; TBI = traumatic brain injury.

SUBMITTED June 29, 2019. ACCEPTED August 12, 2019.

INCLUDE WHEN CITING DOI: 10.3171/2019.8.FOCUS19517. 
ing any one therapeutic option is low, with many institutions choosing drug combinations based on local custom rather than evidence. ${ }^{35}$

Some earlier studies have explored the idea of modulating the autonomic system with drugs that can dampen sympathetic hyperactivity. In the cardiac literature, animal studies involving cardiac sympathectomy decreased the sympathetic drive and damaged the myocardium by regulating hemodynamics. ${ }^{45}$ Ley et al. conducted a multiinstitutional, prospective, observational study administering propranolol, a beta-blocker, in severe TBI. Propranolol demonstrated an association with improved survival, without information regarding functional or quality-of-life outcomes. ${ }^{31}$ The ongoing double-blind randomized clinical trial Decreasing Adrenergic or Sympathetic Hyperactivity after Traumatic Brain Injury (or DASH after TBI) is comparing combination propranolol and clonidine therapy with a placebo in ICU patients. ${ }^{48}$ The results of this trial will add additional evidence regarding the efficacy of these drugs in PSH management and shed light on the interplay between TBI and organ function.

In this paper, we will review the literature on autonomic dysfunction after TBI and possible mechanisms of PSH. Specifically, we will discuss the link among the brain, heart, and kidneys and review data to direct future research on and interventions for TBI-induced autonomic dysfunction.

\section{Anatomical Considerations in Autonomic Dysfunction}

Several areas of the brain, including the hypothalamus, nucleus tractus solitarius (NTS), areas A1 and A5 of the medulla, and the subfornical organ (SFO) contribute to overall control and regulation of the ANS; injury to any one of them could result in autonomic dysregulation. In an early study, Nosaka showed that bilateral hypothalamic lesions in a rat model resulted in hypertension and adrenal hypertrophy, ${ }^{43}$ demonstrating that the hypothalamus is a regulator of sympathetic activity and that damage can result in autonomic dysfunction. This same group demonstrated that lesions to different areas of the hypothalamus resulted in differential effects on the sympathetic nervous system: anteromedian lesions resulted in hypertension and adrenal hypertrophy, whereas posteromedial lesions resulted in hypotension and adrenal atrophy. ${ }^{46}$

The hypothalamic-pituitary-adrenal axis is a crucial contributor to autonomic dysfunction after TBI. In a mild fluid percussion injury model of TBI in rats, activity of the hypothalamic-pituitary-adrenal axis increased after injury, resulting in elevated levels of corticosterone and adrenocorticotropic hormone. ${ }^{24}$ The hypothalamicsympathetic-adrenal-medullary axis may also contribute to posttraumatic ANS dysregulation. In the overpressure blast wave-induced brain injury model in rats, pathways regulating norepinephrine secretion were disturbed. In injured rats, increased NADPH oxidase activity and upregulation of AT1 receptor mRNA expression in the hypothalamus indicated that there was oxidative stress in this region. Also in this model, tyrosine hydroxylase expression was upregulated in the adrenal medulla and in the NTS, which sends and receives inputs from the hypothalamus, and plasma norepinephrine levels were elevated. ${ }^{57}$ This is consistent with prior work demonstrating that the NTS is involved in sympathetic-adrenal excitation, ${ }^{14,30}$ and that the acute pressor response of angiotensin II is mediated through NADPH production of reactive oxygen species in the hypothalamus. ${ }^{18}$

In a related study, Chen et al. reported findings from a rat model of diffuse axonal injury in which they correlated sympathetic activity to indices of oxidative stress in the rostral ventrolateral medulla (RVLM), another key critical region for activity of the sympathetic nervous system. ${ }^{10}$ Following injury, mean arterial pressure and plasma norepinephrine increased markedly, and these changes were associated with parallel increases in RVLM expression of reactive oxygen species and malondialdehyde, and a decrease in superoxide dismutase. Importantly, these changes were all blunted by prior microinjection of Tempol, a superoxide dismutase mimetic, into the RVLM, indicating that oxidative stress within the RVLM contributes to the development of sympathetic hyperactivity following TBI. These studies highlight the importance of these different brain regions in modulating sympathetic outflow and how this regulation can be disrupted in the context of TBI.

Circulating proinflammatory cytokines can play a pivotal role in autonomic and cardiovascular function. ${ }^{20}$ However, these molecules cannot normally cross the blood-brain barrier. Wei and colleagues postulated that the effects of cytokines are mediated via the SFO, which lacks a blood-brain barrier. ${ }^{61}$ Using a rat model in which sham-lesioned rats were compared to SFO-lesioned rats, it was demonstrated that excitatory effects of administered $\mathrm{TNF} \alpha$ and IL-1 $\beta$ on blood pressure, heart rate, and renal sympathetic nerve activity were attenuated in SFO-lesioned rats. These findings suggest that the SFO provides a link between systemic mediators of injury and central mechanisms of autonomic dysfunction. After TBI, however, cytokines and other large molecules could potentially gain direct access to other areas of the brain since TBI can result in increased blood-brain barrier permeability. ${ }^{42}$

The surge of cytokines after brain injury is part of an adaptive response to deal with damaged tissues and maintain brain function. However, the magnitude of this response can contribute to secondary injury, resulting in higher brain cytokine levels compared to serum. ${ }^{40}$ This ubiquitous presence of cytokines, along with global autonomic dysfunction, seen in TBI patients is indicative of an intricate interplay between the cytokines released after injury, the brain regions that respond to these cytokines, and the effects of increased intracranial pressure (ICP) ultimately leading to a heightened sympathetic response.

\section{Impact of TBI-Induced Autonomic Dysfunction on Cardiovascular Physiology}

Elrifai et al. ${ }^{17}$ examined the relationship between brain injury and cardiovascular function by studying the effects of subarachnoid hemorrhage (SAH) on histopathological changes in the heart. Dogs were administered injections of autologous blood into the right frontal lobe and subarachnoid space to study the effects of acute SAH on cardiac 
function. Within 4 hours, there was an increase in overall catecholamine release, ICP, and cardiac output. Additionally, histopathological examination showed myocardial changes within this time frame. This study indicated that an increase in catecholamine release could result in cardiac wall abnormalities and function. Human studies involving brain-dead donors after motor vehicle accidents, gunshot wounds, and spontaneous SAH also demonstrated ultrastructural myocardial sequelae. ${ }^{44}$ Observed changes included a hypercontractile state observed from disruption of sarcomeres, accumulation of mitochondria, and intracellular edema. This damage was postulated to be a result of increased ICP that triggers the release of catecholamines.

The relationship between sympathetic nervous activity and myocardial damage was subsequently investigated in a canine model of SAH. ${ }^{33}$ Levels of noradrenaline, adrenaline, and 3-methoxy-4-hydroxyphenylglycol increased almost twofold, representing sympathetic activity, while serum troponin levels, indicating myocardial damage, increased substantially. Aortic blood pressure and central venous pressure also increased. These results suggested that elevated sympathetic activity induced myocardial damage that contributed to cardiac dysfunction. This study is particularly interesting as it highlights the link between brain injury and sympathetic activity and reinforces the idea that there is a substantial increase in sympathetic tone following trauma to the brain, leading to adverse effects on cardiac function.

Several studies have implicated cardiac dysfunction in the context of TBI, $, 50,51$ and it has been proposed that this might contribute to the cerebral hypoperfusion and secondary injury after TBI. On the other hand, a recent prospective study from Serri and colleagues was unable to identify a significant pattern of cardiac insufficiency. ${ }^{54}$ The reasons for these discrepancies are unknown, and whether brain injury can lead directly to deficits in myocardial function is not yet established. Nonetheless, it is generally well accepted that sympathetic hyperactivity can participate in the pathogenesis of TBI-induced systolic dysregulation in the human heart, ${ }^{29,36}$ and it is further possible that a variety of other factors may also contribute to observed deficits in overall cardiac function. For example, in a recent study, Chaikittisilpa et al. examined the association between the early systemic inflammatory response syndrome and cardiac contractile dysfunction following TBI in a patient cohort with moderate to severe TBI. ${ }^{8}$ They reported that the inflammatory response is common in these patients and that there was a significant correlation with systolic cardiac dysfunction. Thus, while the potential mechanisms are likely complex and remain poorly defined, there is convincing evidence that cardiac dysfunction is a common aggravating factor in the treatment of patients with TBI.

TBI alters hemodynamic function in both early and late phases following injury. Herijgers et al. ${ }^{25}$ utilized an intracranial balloon to increase ICP and monitored regional changes in blood flow. Shortly after TBI, there was an increase in sympathetic activity and catecholamines, which decreased over time. The initial hypersympathetic state resulted in organ vasoconstriction and decreased perfu- sion. By contrast, the late phase manifested with increased vasodilation and a drop in pressures, leading to a hypotensive and underperfused state. ${ }^{13,25}$ The acute effects of brain injury on the arterial baroreflex control of heart rate were examined in a fluid percussion rat model of mild or moderate $\mathrm{TBI} .{ }^{34}$ Interestingly, baroreflex sensitivity was significantly decreased at 10 and 30 minutes following moderate TBI but was unaltered by mild TBI.

\section{Impact of TBI-Induced Autonomic Dysfunction on Renal Physiology}

More recently, the neurorenal axis has gained attention regarding the interactions of brain injury and kidney injury, as summarized in Table 1. Brain injury can affect the kidneys via increased sympathetic tone, catecholamine release, and a hypertensive state after brain trauma. Recent clinical research has shown a link between brain injury and renal function. These studies indicate that acute kidney injury (AKI), hyponatremia, and chronic kidney damage (CKD) occur often in TBI patients.

More than 50 years ago, Nosaka's study demonstrated that altered hemodynamics following an anteromedian lesion of the hypothalamus in rats resulted in renal impairment due to necrosis and edematous swelling of the glomeruli. ${ }^{43}$ Combined with the recent emergence of several clinical articles concerning the link between TBI and kidney injury, the scarcity of basic science research investigating mechanisms of TBI-induced kidney injury is notable. Presently, it is reasonable to postulate that altered hemodynamics do alter overall kidney function. However, it is currently not clear whether this is due to increased sympathetic tone, resulting in renal vasoconstriction and decreased renal perfusion, or to hyperperfusion-induced damage to the glomeruli.

Many clinical observational studies have found augmented renal clearance (ARC) after TBI, yet the mechanisms are largely unknown. ${ }^{15,58}$ In some studies, accelerated renal clearance coincides with an increase in atrial natriuretic peptide (ANP) ${ }^{59}$ The increase in sympathetic activity, which can increase myocardial contractility, is perhaps an explanation for the increase in ANP. In their prospective observational cohort study, Udy et al. showed that TBI resulted in a 20 -fold increase in ANP and a parallel increase in creatinine clearance. ${ }^{59}$ The study also noted an increase in cardiac output, suggesting that the hyperdynamic cardiovascular function is a contributing factor to ARC. It is interesting to note that ANP also increases locally in the brain, especially in areas such as the hypothalamus following trauma with SAH. ${ }^{55}$ Fukui et al. showed that focal brain edema is associated with the increase in ANP levels and may contribute to the cerebral salt-wasting syndrome. ${ }^{21}$ Altered hemodynamics and the presence of increased ANP are indicative of a multifaceted etiology behind ARC.

A study by Minville and colleagues investigated the validity of using serum creatinine and creatinine clearance as a measure of renal function. ${ }^{37}$ In order to determine renal function, serum creatinine values were compared to creatinine clearance values to determine renal filtration states. This study highlighted two critical points that 
TABLE 1. Summary chart of recent clinical studies conducted on the link between TBI and renal function

\begin{tabular}{|c|c|c|c|}
\hline Authors \& Year & Subjects & Method & Findings \\
\hline Dias et al., 2015 & $\begin{array}{l}18 \text { patients } w / T B I \text { in } \\
\text { neurocritical care } \\
\text { unit }\end{array}$ & $\begin{array}{l}\text { ICP monitoring of patients } \\
\mathrm{w} / \mathrm{TBI} \\
\text { Retrospective analysis }\end{array}$ & $\begin{array}{l}\text { - Creatinine clearance was inversely proportional to cerebrovascular } \\
\text { reactivity pressure } \\
\text { - Implications of brain autoregulation impairment \& glomerular filtration } \\
\text { rate }\end{array}$ \\
\hline Udy et al., 2017 & $\begin{array}{l}11 \text { patients w/ TBI \& } \\
\text { no history of kidney } \\
\text { disease }\end{array}$ & $\begin{array}{l}\text { Single-center prospective } \\
\text { observational cohort study }\end{array}$ & $\begin{array}{l}\text { - Elevated ANP } \\
\text { - Elevated creatinine clearance directly proportional to cardiac output } \\
\text { changes } \\
\text { - ARC is likely to complicate TBI prognosis of patients w/ normal plasma } \\
\text { creatinine concentrations }\end{array}$ \\
\hline Moro et al., 2007 & 298 patients $w / T B I$ & Retrospective analysis & $\begin{array}{l}\text { - Hyponatremia after TBI seen in } 16.8 \% \text { of patients w/in first few days of } \\
\text { injury } \\
\text { - Hyponatremia is associated w/ longer hospital stay \& worse prognosis }\end{array}$ \\
\hline $\begin{array}{l}\text { Vedantam et al., } \\
2017\end{array}$ & $\begin{array}{l}588 \text { patients } w / \\
\text { severe TBI }\end{array}$ & Retrospective analysis & $\begin{array}{l}\text { - Hypernatremia detected in } 79.4 \% \text { of patients w/in a week of admission } \\
\text { - Hypernatremia associated w/ AKI \& increased mortality }\end{array}$ \\
\hline Corral et al., 2012 & 224 adult patients & $\begin{array}{l}\text { Observational retrospective } \\
\text { cohort study }\end{array}$ & $\begin{array}{l}\text { - Mortality associated w/ increased ICP \& AKI } \\
\text { - Presence of AKI increased risk of death sixfold }\end{array}$ \\
\hline Moore et al., 2010 & 207 patients w/ TBI & $\begin{array}{l}\text { Prospective data collection \& } \\
\text { retrospective analysis }\end{array}$ & $\begin{array}{l}\text { - Incidence of TBI is around } 10 \% \text { among patients admitted due to TBI } \\
\text { - Patients w/ TBI \& AKI have a mortality rate }>40 \% \text { w/in first few days }\end{array}$ \\
\hline Wu et al., 2017 & 32,152 patients w/ TBI & $\begin{array}{l}\text { Nationwide population-based } \\
\text { cohort study }\end{array}$ & $\begin{array}{l}\text { - Incidence of CKD is higher in TBI patients (proportion w/ CKD was 6.1\%) } \\
\text { - The study highlights long-term renal implications }\end{array}$ \\
\hline
\end{tabular}

should be taken into consideration when examining a link between the ANS and renal function. The first was that creatinine clearance varied dramatically among patients with polytrauma compared to those without polytrauma. The second was that, despite having relatively normal serum creatinine levels, patients with polytrauma exhibited generally higher levels of creatine. Other studies have shown that serum creatine levels can be an inadequate measure of renal filtration in a variety of situations, especially when changes in the renal filtration rate are mild to modest. ${ }^{16,19,26}$ These concepts may at least partially underlie the observed discrepancies regarding renal function in the context of TBI.

Despite clinical studies reporting ARC in patients with TBI, other evidence has suggested that sympathetic hyperactivity in TBI is particularly profound in the kidneys. ${ }^{61}$ Such increases in renal sympathetic nerve activity would be expected to produce an intense effect in the renal microvasculature, presumably resulting in a lowered glomerular filtration rate. Renal autoregulation of blood flow and glomerular filtration is notoriously complex and involves a variety of factors, including the myogenic and tubuloglomerular feedback responses, as well as a third undefined mechanism. ${ }^{28}$ Regulation of cerebral blood flow is likewise complex, and it has been proposed that dysregulation of both vascular beds may involve similar or related mechanisms. ${ }^{53}$ It is not unreasonable to postulate, therefore, that TBI and the resulting autonomic dysregulation may result in chaotic perturbations in both renal and cerebral perfusion, and the crosstalk between the two may exacerbate the overall regulation of perfusion of both organs.

In considering the overall dysregulation of renal function, it is essential to note the incidence of both hyper- and hyponatremia are reported in the context of TBI. Sodium imbalance plays a role in both secondary damage to the brain and AKI. ${ }^{41,60}$ It is uncertain whether altered sodium balance might be related to autonomic dysfunction itself or another independent effect of brain injury on renal function. Regardless, sodium imbalance is well established in brain injury, especially the concept of cerebral salt-wasting syndrome and syndrome of inappropriate antidiuretic hormone secretion (SIADH) resulting from posterior pituitary damage. ${ }^{1}$ In some studies, hyponatremia after TBI can lower plasma oncotic pressures, resulting in vasogenic edema. ${ }^{41}$ This could be due to SIADH, which acts via dilution effects causing excessive water retention in kidneys. Similarly, in one study, hypernatremia was found in $79.4 \%$ of patients with severe TBI, either spontaneously or as a result of medical therapy, and was associated with an increased mortality rate. ${ }^{60}$ Interestingly, previous studies have found that hypernatremia can cause vasoconstriction in the kidneys and a reduction in the glomerular filtration rate. ${ }^{22}$ Further studies are needed to examine the link between sodium imbalance, TBI, and autonomic dysfunction.

\section{Organ System Dysfunction in TBI}

The pathophysiology of multiorgan dysfunction after TBI is not well understood, as it could arise as a direct effect of the primary injury (e.g., kidney laceration) or as a secondary effect from the medical therapies for TBI (e.g., mannitol-induced renal failure). Animal models are a valuable resource for identifying the mechanisms underlying multiorgan dysfunction after TBI. A summary of notable animal studies is provided in Table 2 .

A link between TBI and AKI is widely recognized. ${ }^{13,15,39}$ 
TABLE 2. Summary of animal models of brain injury and effects on the sympathetic nervous system

\begin{tabular}{|c|c|c|c|}
\hline Authors \& Year & Subjects & Model & Findings \\
\hline Chen et al., 2019 & Rat & $\begin{array}{l}\text { Diffuse axonal injury by lateral/ } \\
\text { rotational displacement }\end{array}$ & $\begin{array}{l}\text { - Elevated MAP \& plasma NE } \\
\text { - Elevated ROS, MDA, \& reduced SOD in the RVLM } \\
\text { - Effects blunted by pretreatment w/ Tempol microinjected into the RVLM }\end{array}$ \\
\hline Elrifai et al., 1996 & Dog & $\mathrm{SAH}$ & $\begin{array}{l}\text { - Increase in catecholamine release } \\
\text { - Increase cardiac output } \\
\text { - Myocardial changes } \\
\text { - Increased ICP }\end{array}$ \\
\hline Herijgers et al., 1996 & Rat & $\begin{array}{l}\text { Intracranial balloon-induced brain } \\
\text { death \& colored-microsphere } \\
\text { monitoring of blood flow }\end{array}$ & $\begin{array}{l}\text { - Early increase in the sympathetic nervous system shown by } \times 57 \text { higher NE } \\
\text { levels } \\
\text { - Late dramatic decrease in the sympathetic nervous system as shown by } \\
\text { decreased NE from basal levels }\end{array}$ \\
\hline Masuda et al., 2002 & Dog & $\begin{array}{l}\mathrm{SAH} \text {-perforation of the basilar } \\
\text { artery }\end{array}$ & $\begin{array}{l}\text { - Twofold increase in plasma levels of NE, ADR, 3MHPG } \\
\text { - Increase in plasma levels of NE, ADR, 3MHPG, \& troponin } \\
\text { - Increase in aortic BP \& CVP }\end{array}$ \\
\hline Mirzayan et al., 2008 & Mouse & Controlled cortical impact & $\begin{array}{l}\text { - Histopathology revealed edematous lung \& liver changes } \\
\text { - No histopathological findings in the kidneys were found }\end{array}$ \\
\hline Tümer et al., 2013 & Rat & Overpressure blast injury & $\begin{array}{l}\text { - Increase in NADPH oxidase } \\
\text { - Increase in ANG1 R expression in the hypothalamus } \\
\text { - Elevated tyrosine hydroxylase expression in NTS } \\
\text { - Increase in plasma NE } \\
\text { - Increase in catecholamine biosynthetic enzymes \& NPY in the adrenal medulla }\end{array}$ \\
\hline Wei et al., 2013 & Rat & SFO lesion & $\begin{array}{l}\text { - Decrease in sympathetic activity in SFO-lesioned rats after TNF } \alpha \text { \& IL- } \beta \\
\text { administration } \\
\text { - Increase in sympathetic activity in sham-lesioned rats after TNF } \alpha \text { \& IL- } \beta \\
\text { administration } \\
\text { - SFO mediates sympathetic \& hemodynamic responses to inflammatory } \\
\text { cytokines }\end{array}$ \\
\hline
\end{tabular}

$\mathrm{ADR}=$ adrenaline; $\mathrm{ANG1} \mathrm{R}=$ angiotensin 1 receptor; $\mathrm{BP}=$ blood pressure; $\mathrm{CVP}=$ central venous pressure; $\mathrm{MAP}=$ mean arterial pressure; $\mathrm{MDA}=$ malondialdehyde; $\mathrm{NE}=$ norepinephrine; $\mathrm{NPY}=$ neuropeptide $\mathrm{Y} ; \mathrm{ROS}$ = reactive oxygen species; SOD = superoxide dismutase; 3MHPG = 3-methoxy-4-hydroxyphenylglycol.

A retrospective epidemiological study examined TBI patients who presented with a Glasgow Coma Scale score lower than 13 and correlated outcomes to renal function. A large cohort of patients was evaluated using RIFLE (the Risk, Injury, Failure, Loss of kidney function, and Endstage kidney disease) criteria to comment on renal dysfunction. ${ }^{5}$ This study ultimately found that the incidence of AKI after TBI is around $8 \%$ and that the mortality rate is around $40 \%$ in patients who have had both TBI and AKI. ${ }^{39}$ This mortality rate suggests that AKI following TBI is a factor in poor outcome and that targeting the mechanism of what causes the AKI may be beneficial in improving patients' prognosis. It is also worth noting that TBI can cause more permanent damage to the kidneys, culminating in chronic kidney disease. A nationwide populationbased cohort study in Taiwan reported that TBI increased the incidence of CKD. ${ }^{62}$

AKI is associated with the small-vessel damage in both the brain and kidneys that can result in ischemia. Since AKI is an inflammatory condition, increased inflammatory cytokines and thrombin generation can exacerbate secondary damage after TBI. ${ }^{52}$ It is therefore relevant to address the available evidence regarding the reciprocal relationship between TBI and AKI. The brain and kidneys are highly perfused organs and usually have low vascu- lar resistance. Therefore, upstream pressure changes can drastically impact these organs. This shared characteristic between the two organs shows that hemodynamic regulatory mechanisms may be related. Additionally, crosstalk between the brain and kidneys may provide insight into ongoing dysregulation. ${ }^{27,42}$ Information regarding vascular changes in one organ can provide crucial information about the function of the other. ${ }^{47}$

Inflammation that occurs after brain injury can result in a breakdown in the blood-brain barrier and result in leakage of cytokines into the systemic circulation, which affects other organs. ${ }^{23}$ The release of systemic cytokines can then enter the brain through the same damaged bloodbrain barrier. Transplant studies have shown an increased risk of rejection after kidney transplants from brain-dead donors due to circulating cytokines. ${ }^{52}$

Elevated ICP, which is common after TBI, causes increased sympathetic activity resulting in hypertension, increased heart rate, and catecholamine hypersecretion, and hence can result in organ dysfunction. Catecholamines increase the contractility of the heart despite an already increased vascular resistance. ${ }^{6}$ Hypotension following brain injury is also associated with morbidity in TBI patients. ${ }^{13}$ The prevailing hypothesis is that an exhaustion phase follows the hyperdynamic state. In the exhaustion phase, 


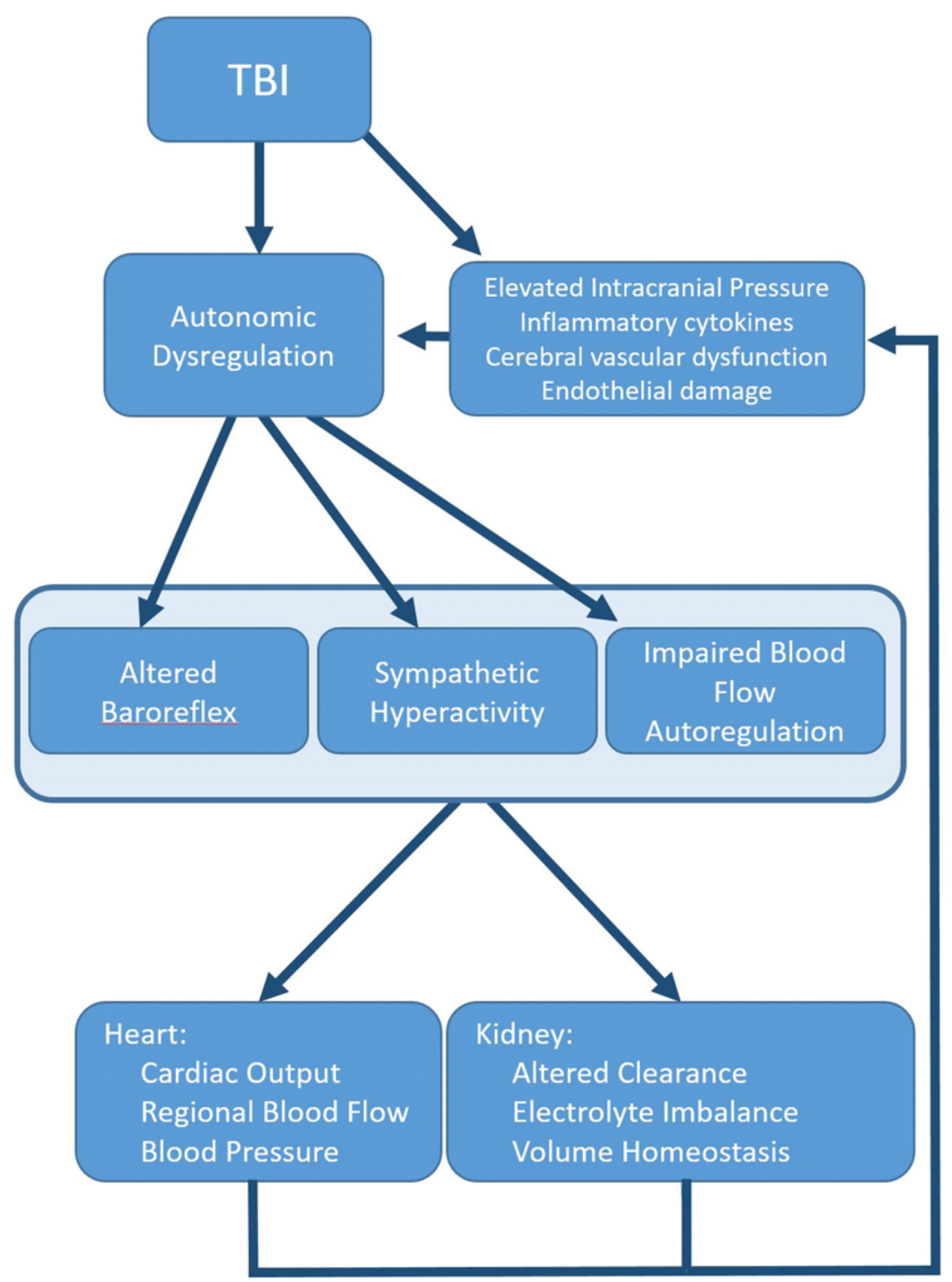

FIG. 1. Diagram summarizing the central concepts outlined in this review, suggesting that brain injury can produce autonomic hyperactivity and imbalance. The result would be disruption of whole-body and organ system homeostasis, with a negative impact on recovery from the initial injury and a worsening prognosis.

catecholamines and vascular resistance are reduced, leading to hypovolemia and severely impaired cardiovascular function.$^{45}$ As a result, compromised hemodynamic stability further complicates perfusion in critical organs. ${ }^{25}$

Parasympathetic activation via vagal nerve stimulation has also been proposed as a strategy to dampen the adverse effects of TBI-induced sympathetic hyperactivity. Lopez et al. speculated that stimulating the parasympathetic response may help alleviate the adverse effects on the blood-brain barrier that occur with hypersympathetic autonomic dysfunction by decreasing its disruption. ${ }^{32}$ Us- ing a weight-drop model in mice, it was demonstrated that vascular permeability was increased fourfold in mice with TBI compared with sham mice and that vagal nerve stimulation blunted this by decreasing the upregulation of AQP4 channels. Increased vascular permeability is a possible cause of worsening ICP that can lead to a further increase in sympathetic activity and altered hemodynamics in the heart and kidneys. Previous studies have explored autonomic dysfunction following TBI, which inevitably leads to systemic inflammation and gastrointestinal dysfunction and that that this could be alleviated with vagal nerve elec- 
trical stimulation. ${ }^{3,4}$ While the role of the parasympathetic system in PSH is unclear, these studies suggest it is a potential therapeutic target.

\section{Conclusions}

The pathophysiology of autonomic dysfunction following TBI is incompletely understood. Here, we have detailed the anatomical considerations and highlighted the crosstalk among the brain, heart, and kidneys that can contribute to TBI-related autonomic dysfunction. Most research suggests a common theme that brain injury is commonly associated with increases in sympathetic activity, which can alter the regulatory function of critical organs such as the heart and kidneys via hemodynamic changes. It is also likely that brain injury alters the fine balance between the sympathetic and parasympathetic arms of the autonomic nervous system, resulting in an imbalance of the homeostatic mechanisms that maintain normal organ system function and their interactions with each other, as outlined in Fig. 1. Autonomic dysregulation can cause changes in cardiac output, disruptions in regional blood flow, alteration in renal clearance, and imbalance in electrolytes that can cause a reciprocal loop of further autonomic dysfunction. However, evidence in the current literature is often contradictory, and hence more translational research is warranted, as understanding of these relationships and potential therapeutic targets will inevitably improve patient outcomes.

\section{References}

1. Agha A, Thornton E, O'Kelly P, Tormey W, Phillips J, Thompson CJ: Posterior pituitary dysfunction after traumatic brain injury. J Clin Endocrinol Metab 89:5987-5992, 2004

2. Baguley IJ, Perkes IE, Fernandez-Ortega JF, Rabinstein AA, Dolce G, Hendricks HT: Paroxysmal sympathetic hyperactivity after acquired brain injury: consensus on conceptual definition, nomenclature, and diagnostic criteria. J Neurotrauma 31:1515-1520, 2014

3. Bansal V, Costantini T, Kroll L, Peterson C, Loomis W, Eliceiri B, et al: Traumatic brain injury and intestinal dysfunction: uncovering the neuro-enteric axis. $\mathbf{J}$ Neurotrauma 26:1353-1359, 2009

4. Bansal V, Costantini T, Ryu SY, Peterson C, Loomis W, Putnam J, et al: Stimulating the central nervous system to prevent intestinal dysfunction after traumatic brain injury. J Trauma 68:1059-1064, 2010

5. Bellomo R, Ronco C, Kellum JA, Mehta RL, Palevsky P: Acute renal failure - definition, outcome measures, animal models, fluid therapy and information technology needs: the Second International Consensus Conference of the Acute Dialysis Quality Initiative (ADQI) Group. Crit Care 8:R204-R212, 2004

6. Belzberg H, Shoemaker WC, Wo CCJ, Nicholls TP, Dang ABC, Zelman V, et al: Hemodynamic and oxygen transport patterns after head trauma and brain death: implications for management of the organ donor. J Trauma 63:1032-1042, 2007

7. Carney N, Totten AM, O'Reilly C, Ullman JS, Hawryluk $\mathrm{GW}$, Bell MJ, et al: Guidelines for the management of severe traumatic brain injury, fourth edition. Neurosurgery 80:615,2017

8. Chaikittisilpa N, Krishnamoorthy V, Lele AV, Qiu Q, Vavilala MS: Characterizing the relationship between systemic inflammatory response syndrome and early cardiac dysfunction in traumatic brain injury. J Neurosci Res 96:661-670, 2018
9. Cheah CF, Kofler M, Schiefecker AJ, Beer R, Klug G, Pfausler B, et al: Takotsubo cardiomyopathy in traumatic brain injury. Neurocrit Care 26:284-291, 2017

10. Chen J, Chen W, Han K, Qi E, Chen R, Yu M, et al: Effect of oxidative stress in rostral ventrolateral medulla on sympathetic hyperactivity after traumatic brain injury. Eur J Neurosci 50:1972-1980, 2019

11. Clifton GL, McCormick WF, Grossman RG: Neuropathology of early and late deaths after head injury. Neurosurgery 8:309-314, 1981

12. Clifton GL, Robertson CS, Kyper K, Taylor AA, Dhekne RD, Grossman RG: Cardiovascular response to severe head injury. J Neurosurg 59:447-454, 1983

13. Corral L, Javierre CF, Ventura JL, Marcos P, Herrero JI, Mañez R: Impact of non-neurological complications in severe traumatic brain injury outcome. Crit Care 16:R44, 2012

14. Del Rey A, Chrousos GP, Besedovsky HO (eds): The Hypothalamus-Pituitary-Adrenal Axis. Amsterdam: Elsevier, 2008, pp 394

15. Dias C, Gaio AR, Monteiro E, Barbosa S, Cerejo A, Donnelly J, et al: Kidney-brain link in traumatic brain injury patients? A preliminary report. Neurocrit Care 22:192-201, 2015

16. Doolan PD, Alpen EL, Theil GB: A clinical appraisal of the plasma concentration and endogenous clearance of creatinine. Am J Med 32:65-79, 1962

17. Elrifai AM, Bailes JE, Shih SR, Dianzumba S, Brillman J: Characterization of the cardiac effects of acute subarachnoid hemorrhage in dogs. Stroke 27:737-742, 1996

18. Erdös B, Broxson CS, King MA, Scarpace PJ, Tümer N: Acute pressor effect of central angiotensin II is mediated by $\mathrm{NAD}(\mathrm{P}) \mathrm{H}$-oxidase-dependent production of superoxide in the hypothalamic cardiovascular regulatory nuclei. J Hypertens 24:109-116, 2006

19. Erley CM, Bader BD, Berger ED, Vochazer A, Jorzik JJ, Dietz K, et al: Plasma clearance of iodine contrast media as a measure of glomerular filtration rate in critically ill patients. Crit Care Med 29:1544-1550, 2001

20. Felder RB: Mineralocorticoid receptors, inflammation and sympathetic drive in a rat model of systolic heart failure. Exp Physiol 95:19-25, 2010

21. Fukui S, Nawashiro H, Otani N, Ooigawa H, Toyooka T, Tsuzuki N, et al: Focal brain edema and natriuretic peptides in patients with subarachnoid hemorrhage. Acta Neurochir Suppl 86:489-491, 2003

22. Gerber JG, Branch RA, Nies AS, Hollifield JW, Gerkens JF: Influence of hypertonic saline on canine renal blood flow and renin release. Am J Physiol 237:F441-F446, 1979

23. Ghirnikar RS, Lee YL, Eng LF: Inflammation in traumatic brain injury: role of cytokines and chemokines. Neurochem Res 23:329-340, 1998

24. Griesbach GS, Hovda DA, Tio DL, Taylor AN: Heightening of the stress response during the first weeks after a mild traumatic brain injury. Neuroscience 178:147-158, 2011

25. Herijgers P, Leunens V, Tjandra-Maga TB, Mubagwa K, Flameng W: Changes in organ perfusion after brain death in the rat and its relation to circulating catecholamines. Transplantation 62:330-335, 1996

26. Hoste EAJ, Damen J, Vanholder RC, Lameire NH, Delanghe JR, Van den Hauwe K, et al: Assessment of renal function in recently admitted critically ill patients with normal serum creatinine. Nephrol Dial Transplant 20:747-753, 2005

27. Ito S, Nagasawa T, Abe M, Mori T: Strain vessel hypothesis: a viewpoint for linkage of albuminuria and cerebrocardiovascular risk. Hypertens Res 32:115-121, 2009

28. Just A: Mechanisms of renal blood flow autoregulation: dynamics and contributions. Am J Physiol Regul Integr Comp Physiol 292:R1-R17, 2007

29. Krishnamoorthy V, Rowhani-Rahbar A, Chaikittisilpa N, 
Gibbons EF, Rivara FP, Temkin NR, et al: Association of early hemodynamic profile and the development of systolic dysfunction following traumatic brain injury. Neurocrit Care 26:379-387, 2017

30. Kvetnansky R, Sabban EL, Palkovits M: Catecholaminergic systems in stress: structural and molecular genetic approaches. Physiol Rev 89:535-606, 2009

31. Ley EJ, Leonard SD, Barmparas G, Dhillon NK, Inaba K, Salim A, et al: Beta blockers in critically ill patients with traumatic brain injury: results from a multicenter, prospective, observational American Association for the Surgery of Trauma study. J Trauma Acute Care Surg 84:234-244, 2018

32. Lopez NE, Krzyzaniak MJ, Costantini TW, Putnam J, Hageny AM, Eliceiri B, et al: Vagal nerve stimulation decreases blood-brain barrier disruption after traumatic brain injury. J Trauma Acute Care Surg 72:1562-1566, 2012

33. Masuda T, Sato K, Yamamoto S, Matsuyama N, Shimohama T, Matsunaga A, et al: Sympathetic nervous activity and myocardial damage immediately after subarachnoid hemorrhage in a unique animal model. Stroke 33:1671-1676, 2002

34. McMahon CG, Kenny R, Bennett K, Little R, Kirkman E: Effect of acute traumatic brain injury on baroreflex function. Shock 35:53-58, 2011

35. Meyfroidt G, Baguley IJ, Menon DK: Paroxysmal sympathetic hyperactivity: the storm after acute brain injury. Lancet Neurol 16:721-729, 2017

36. Mierzewska-Schmidt M, Gawecka A: Neurogenic stunned myocardium-do we consider this diagnosis in patients with acute central nervous system injury and acute heart failure? Anaesthesiol Intensive Ther 47:175-180, 2015

37. Minville V, Asehnoune K, Ruiz S, Breden A, Georges B, Seguin T, et al: Increased creatinine clearance in polytrauma patients with normal serum creatinine: a retrospective observational study. Crit Care 15:R49, 2011

38. Mirzayan MJ, Probst C, Krettek C, Samii M, Pape HC, van Griensven M, et al: Systemic effects of isolated brain injury: an experimental animal study. Neurol Res 30:457-460, 2008

39. Moore EM, Bellomo R, Nichol A, Harley N, Macisaac C, Cooper DJ: The incidence of acute kidney injury in patients with traumatic brain injury. Ren Fail 32:1060-1065, 2010

40. Morganti-Kossman MC, Lenzlinger PM, Hans V, Stahel P, Csuka E, Ammann E, et al: Production of cytokines following brain injury: beneficial and deleterious for the damaged tissue. Mol Psychiatry 2:133-136, 1997

41. Moro N, Katayama Y, Igarashi T, Mori T, Kawamata T, Kojima J: Hyponatremia in patients with traumatic brain injury: incidence, mechanism, and response to sodium supplementation or retention therapy with hydrocortisone. Surg Neurol 68:387-393, 2007

42. Nongnuch A, Panorchan K, Davenport A: Brain-kidney crosstalk. Crit Care 18:225, 2014

43. Nosaka S: Hypertension induced by extensive medial anteromedian hypothalamic destruction in the rat. Jpn Circ J 30:509-523, 1966

44. Novitzky D, Rhodin J, Cooper DK, Ye Y, Min KW, DeBault L: Ultrastructure changes associated with brain death in the human donor heart. Transpl Int 10:24-32, 1997

45. Novitzky D, Wicomb WN, Cooper DK, Rose AG, Reichart B: Prevention of myocardial injury during brain death by total cardiac sympathectomy in the Chacma baboon. Ann Thorac Surg 41:520-524, 1986

46. Okamoto K, Nosaka S, Yamori Y: Experimental hypertension and hypotension induced by hypothalamic destruction in the rat. Jpn Circ J 29:251-261, 1965

47. Ono M, Arnaoutakis GJ, Fine DM, Brady K, Easley $\mathrm{RB}$, Zheng Y, et al: Blood pressure excursions below the cerebral autoregulation threshold during cardiac surgery are associated with acute kidney injury. Crit Care Med 41:464471, 2013

48. Patel MB, McKenna JW, Alvarez JM, Sugiura A, Jenkins JM, Guillamondegui OD, et al: Decreasing adrenergic or sympathetic hyperactivity after severe traumatic brain injury using propranolol and clonidine (DASH After TBI Study): study protocol for a randomized controlled trial. Trials 13:177, 2012

49. Perkes I, Baguley IJ, Nott MT, Menon DK: A review of paroxysmal sympathetic hyperactivity after acquired brain injury. Ann Neurol 68:126-135, 2010

50. Prathep S, Sharma D, Hallman M, Joffe A, Krishnamoorthy V, Mackensen GB, et al: Preliminary report on cardiac dysfunction after isolated traumatic brain injury. Crit Care Med 42:142-147, 2014

51. Qian R, Yang W, Wang X, Xu Z, Liu X, Sun B: Evaluation of cerebral-cardiac syndrome using echocardiography in a canine model of acute traumatic brain injury. Am J Cardiovasc Dis 5:72-76, 2015

52. Sánchez-Fructuoso AI, Prats D, Marques M, Blanco J, Torrente J, Conesa J, et al: Does donor brain death influence acute vascular rejection in the kidney transplant? Transplantation 78:142-146, 2004

53. Schiller A, Covic A: Kidney and brain-a renal perspective of 'Les Liaisons Dangereuses.' Nephrol Dial Transplant 25:1370-1373, 2010

54. Serri K, El Rayes M, Giraldeau G, Williamson D, Bernard F: Traumatic brain injury is not associated with significant myocardial dysfunction: an observational pilot study. Scand J Trauma Resusc Emerg Med 24:31, 2016

55. Tanaka I, Misono KS, Inagami T: Atrial natriuretic factor in rat hypothalamus, atria and plasma: determination by specific radioimmunoassay. Biochem Biophys Res Commun 124:663-668, 1984

56. Taylor CA, Bell JM, Breiding MJ, Xu L: Traumatic brain injury-related emergency department visits, hospitalizations, and deaths-United States, 2007 and 2013. MMWR Surveill Summ 66:1-16, 2017

57. Tümer N, Svetlov S, Whidden M, Kirichenko N, Prima $\mathrm{V}$, Erdos B, et al: Overpressure blast-wave induced brain injury elevates oxidative stress in the hypothalamus and catecholamine biosynthesis in the rat adrenal medulla. Neurosci Lett 544:62-67, 2013

58. Udy A, Boots R, Senthuran S, Stuart J, Deans R, LassigSmith M, et al: Augmented creatinine clearance in traumatic brain injury. Anesth Analg 111:1505-1510, 2010

59. Udy AA, Jarrett P, Lassig-Smith M, Stuart J, Starr T, Dunlop R, et al: Augmented renal clearance in traumatic brain injury: a single-center observational study of atrial natriuretic peptide, cardiac output, and creatinine clearance. J Neurotrauma 34:137-144, 2017

60. Vedantam A, Robertson CS, Gopinath SP: Morbidity and mortality associated with hypernatremia in patients with severe traumatic brain injury. Neurosurg Focus 43(5):E2, 2017

61. Wei SG, Zhang ZH, Beltz TG, Yu Y, Johnson AK, Felder RB: Subfornical organ mediates sympathetic and hemodynamic responses to blood-borne proinflammatory cytokines. Hypertension 62:118-125, 2013

62. Wu CL, Kor CT, Chiu PF, Tsai CC, Lian IB, Yang TH, et al: Long-term renal outcomes in patients with traumatic brain injury: a nationwide population-based cohort study. PLoS One 12:e0171999, 2017

\section{Disclosures}

Dr. Foreman reports being a consultant for Minnetronix Medical Inc. and receiving payments from UCB for taking part in the speakers' bureau. 


\section{Author Contributions}

Conception and design: Ngwenya, Khalid, McGuire, Robson, Foreman, Lorenz. Acquisition of data: Khalid, Yang, Lorenz. Analysis and interpretation of data: Khalid, Yang, Lorenz. Drafting the article: Ngwenya, Khalid, Yang, Robson, Lorenz. Critically revising the article: Ngwenya, Yang, McGuire, Robson, Foreman, Lorenz. Reviewed submitted version of manuscript: Ngwenya, Khalid, McGuire, Robson, Foreman, Lorenz. Approved the final version of the manuscript on behalf of all authors: Ngwenya.

\section{Correspondence}

Laura B. Ngwenya: University of Cincinnati College of Medicine, Cincinnati, OH. laura.ngwenya@uc.edu. 